\title{
Growth Responses and Metal Accumulation in an Ornamental Plant (Osmanthus fragrans var. thunbergii) Submitted to Different Cd Levels
}

\author{
Fu-Zhong Wu, Wan-Qin Yang, Jian Zhang, and Li-Qiang Zhou \\ Faculty of Forestry, Sichuan Agricultural University, Ya'an 625014, China \\ Correspondence should be addressed to Wan-Qin Yang, scyangwq@163.com
}

Received 24 February 2011; Accepted 7 April 2011

Academic Editors: A. Chappelka and S. Loppi

Copyright (c) 2011 Fu-Zhong Wu et al. This is an open access article distributed under the Creative Commons Attribution License, which permits unrestricted use, distribution, and reproduction in any medium, provided the original work is properly cited.

\begin{abstract}
To characterize the effects of $\mathrm{Cd}$ supplies on the accumulation efficiency of $\mathrm{Cd}, \mathrm{Pb}, \mathrm{Zn}$, and $\mathrm{Cu}$ in an ornamental plant (osmanthus, Osmanthus fragrans var. thunbergii), a pot experiment using current-year osmanthus in field was carried out in western China. Biomass and its components showed a decreasing tendency as Cd supply increased, though insignificant differences were observed between treatments with a low and no Cd supply. Cd supplies increased the concentrations of $\mathrm{Cd}$ and $\mathrm{Pb}$ in plants, but the concentrations of $\mathrm{Zn}$ and $\mathrm{Cu}$ in plant showed a decreasing tendency with the increase of $\mathrm{Cd}$ supplies. Cd supplies also increased $\mathrm{Cd}$ accumulation for the plant, although the highest $\mathrm{Cd}$ accumulation was observed at a low $\mathrm{Cd}$ supply (T1). A higher Pb accumulation in the osmanthus was also detected in T1 than the other treatments. However, $\mathrm{Zn}$ and $\mathrm{Cu}$ accumulations decreased with the increase of $\mathrm{Cd}$ supplies. The examined osmanthus showed relative higher $\mathrm{Cd}$ and $\mathrm{Pb}$ transfer efficiencies in the presence of $\mathrm{Cd}$ supplies, but $\mathrm{Cd}$ supplies can limit the transfer of $\mathrm{Zn}$ and $\mathrm{Cu}$. The results suggested that the examined osmanthus has potential for use in metal-contaminated environments due to phytoremediation application in the soil.
\end{abstract}

\section{Introduction}

One of the main environmental problems in many developing countries is the increasing pollution by toxic metals related to increased industrial activity and the heavy use of chemical fertilizer, pesticides, and herbicides in agriculture [1-3]. Bioaccumulation of toxic metals in humans can result in several harmful symptoms in gastrointestinal, neurological, and immunological systems $[4,5]$. The most dangerous metals include the so-called "toxic trio": $\mathrm{Cd}, \mathrm{Pb}$, and $\mathrm{Hg}$, for which no biological function has been found [6-8]. Besides them, there is a long list of other metals which although essential in low doses, become toxic in high doses, such as $\mathrm{Zn}, \mathrm{Cu}$, and $\mathrm{Mn}[5]$.

Many soils are receiving lots of toxic metals with high pollution, but many others only display pollution with one or two metal. Compared with other toxic metals, $\mathrm{Cd}$ is not an essential nutrient in higher plants, and the exposure to relatively low concentrations results in high toxicity to plants and animals [9]. Unfortunately, Cd is the most common toxic metal in many areas worldwide. Since Cd stress often decreases plant growth [10], exposure to $\mathrm{Cd}$ can decrease accumulation of other toxic metals (such as $\mathrm{Pb}, \mathrm{Zn}$, and $\mathrm{Cu}$ ) in plants. Moreover, the study on tobacco found that there were negative correlations as $\mathrm{Cd}$ accumulation increased, $\mathrm{Zn}$ accumulation decreased, implying that some heavy metals were antagonistic [11]. However, a few studies have found that a low concentration of $\mathrm{Cd}$ can stimulate plant growth [12], consequently increasing the accumulation of other metals. As yet, it is not only the presence of various toxic metals that might enlarge the toxicity of metals, but also the influence that one heavy metal can have in facilitating or limiting the accumulation of the others [13]. The lack of a mean for removing these complicated toxic metals from soil is the crux of the current problem.

A variety of the engineering and biological technologies have been developed to remedy the contaminated ecosystems $[10,14,15]$. Phytoextraction, the use of plants to extract, sequester, and/or detoxify hazardous heavy metals from different media (soil, water, and air), is regarded as 
a practical and affordable alternative for remediation of polluted sites [16-18]. According to previous studies, there are two different ways in phytoextraction. One is the use of a hyperaccumulator that accumulates toxic metals in plant organs with high biomass production such as poplar and willow [19-21]; the other is the use of a phytoextractor that concentrates toxic metals in the organisms with high metal concentration such as Lonicera japonica [22]. However, the problem lies in harvesting and disposal of the metal-contaminated biomass. If animals consume the contaminated biomass, biomagnification occurs on each level of the trophic chain and can pose harm to humans as the final consumers in using both remediation methods [4]. Many ornamental wood-plants can tolerant the environment with high toxic metal concentration and long growth time [13], showing relatively high growth characteristics and metal accumulation. Additionally, the ornamental wood-plants are not part of the human food chain, but they can extract several toxic metals from soil at the same time, resulting in particular economic and ecological values for polluted environment. Accordingly, the use of ornamental woodplants could provide an improved method for remedying polluted environment.

Osmanthus (Osmanthus fragrans var. thunbergii) is a valuable ornamental wood-plant popular in urban gardens and landscaping in many cadmium-contaminated regions of the Yangtze River Basin. With the expansion of industry and agriculture, increasing contamination of $\mathrm{Cd}, \mathrm{Pb}, \mathrm{Zn}$, and $\mathrm{Cu}$ has limited the economic and social development in this region [23, 24]. Little information has been available on the adaptation of osmanthus to Cd contamination, and far less has focused on the effects of $\mathrm{Cd}$ contamination on the accumulation of other metals, such as $\mathrm{Pb}, \mathrm{Zn}$, and $\mathrm{Cu}$. Therefore, it is hypothesized that Cd contamination could limit the growth of osmanthus, and subsequently decrease accumulation of other metals. The objectives of this study were (1) to characterize the effects of different cadmium levels on the growth of osmanthus and (2) to understand the accumulation characteristics of $\mathrm{Cd}, \mathrm{Pb}, \mathrm{Zn}$, and $\mathrm{Cu}$ in osmanthus under different levels of cadmium stress.

\section{Material and Methods}

2.1. Field Site and Soil Characterization. The field potculture experiment was located at the State Key Laboratory of Forestry Eco-engineering in Sichuan Agricultural University $\left(102^{\circ} 59^{\prime} \mathrm{E}, 29^{\circ} 58^{\prime} \mathrm{N}\right.$, a.s.l. $\left.620 \mathrm{~m}\right)$. The site is subtropical with a warm and moist climate, $16^{\circ} \mathrm{C}$ average annual temperature, $1732 \mathrm{~mm}$ average annual precipitation, $838 \mathrm{~mm}$ average transpiration, and 294 frostless days per year [25]. Samples of purple soil (dystric purple-udic cambisols) were collected from the surface $(0-20 \mathrm{~cm})$ in a field near the university and near the Qingyi River, respectively. The sampled soil characteristics were measured with 4.85 for $\mathrm{pH}, 20.03 \mathrm{~g} \mathrm{~kg}^{-1}$ for organic carbon, $1.28 \mathrm{~g} \mathrm{~kg}^{-1}$ for total $\mathrm{N}$, $0.45 \mathrm{~g} \mathrm{~kg}^{-1}$ for total $\mathrm{P}, 3.05 \mathrm{~g} \mathrm{~kg}^{-1}$ for total $\mathrm{K}, 2.95 \mathrm{mg} \mathrm{kg}^{-1}$ for $\mathrm{Cd}$, $54.91 \mathrm{mg} \mathrm{kg}^{-1}$ for $\mathrm{Pb}, 123.52 \mathrm{mg} \mathrm{kg}^{-1}$ for $\mathrm{Zn}$, and $29.51 \mathrm{mg} \mathrm{kg}^{-1}$ for $\mathrm{Cu}$.
2.2. Experimental Design. $25 \mathrm{~kg}$ soil samples were air dried and sieved by a $4-\mathrm{mm}$ plastic sieve, and then placed into porcelain pots $(25 \mathrm{~cm}$ height and $36 \mathrm{~cm}$ in diameter) after mixing with a Cd solution. In order to analysis the tolerance ability and growth adaptation of osmanthus to $\mathrm{Cd}$ contamination, five levels of Cd (CK: 0, T1: 25, T2: 50, T3: 100, and T4: $200 \mathrm{mg} \mathrm{Cd} \mathrm{kg}^{-1}$ dry soil) as $\mathrm{CdCl}_{2} \cdot 2 \cdot 5 \mathrm{H}_{2} \mathrm{O}$ solution was applied to the pots. Meanwhile, $6 \mathrm{~g}$ urea and $3 \mathrm{~g} \mathrm{KH}_{2} \mathrm{PO}_{4}$ were applied to each pot to avoid nutrient limitation. Current year osmanthus with around $12 \mathrm{~cm}$ height and $1.80 \mathrm{~mm}$ basal diameter from a noncontaminated nursery in the Key Laboratory of Forestry Eco-engineering in Sichuan Agricultural University were transferred directly to the porcelain pots on March 3, 2008. Five similar osmanthus in the same living condition were used to determine the average dry mass of the potted plants. The plants were grown outdoors to simulate field conditions. Each treatment was arranged in five replicates. The experiment was terminated at the end of the growing period on November 28, 2008. The total growth time was 270 days.

2.3. Measurements and Calculations. Fallen leaves were collected every month during the experiment. Biomass was determined after being oven dried at $70^{\circ} \mathrm{C}$ for at least $36 \mathrm{~h}$. The plants were harvested in each treatment when the experiment was terminated. The harvested plants were rinsed with tap water, and the roots were immersed in $20 \mathrm{mM} \mathrm{Na}_{2}$ EDTA for $15 \mathrm{~min}$ to remove cadmium that adhered to the root surface $[22,26]$, and then the whole plant was rinsed with deionized water. The leaves, roots, and shoots were divided and dried in an oven for at least $48 \mathrm{~h}$ at $70^{\circ} \mathrm{C}$ to constant weight for biomass determination. Initial average dry mass of the plants was subtracted from final dry mass for biomass determination. Total plant biomass was the sum of the litter, leaf, root and shoot. The oven-dried samples were ground finely by a porcelain mortar for metal analysis.

The powder of samples were digested with a concentrated acid mixture of $\mathrm{HNO}_{3}-\mathrm{HClO}_{4}(3: 1, \mathrm{v} / \mathrm{v})$ and heated at $160^{\circ} \mathrm{C}$ for $5 \mathrm{~h}$. After cooling, the extract was diluted, filtered, and made up to $25 \mathrm{~mL}$ with $5 \% \mathrm{HNO}_{3}$ [27]. The concentrations of $\mathrm{Cd}, \mathrm{Pb}, \mathrm{Zn}$, and $\mathrm{Cu}$ in the extract were determined by Inductive Coupled Plasma Atomic Emission Spectroscopy (ICP-AES IRIS IntrepidXSP; Thermo Electron Company, USA). The analysis was carried out in triplicate.

The bioaccumulation coefficient (BC) or enrichment factor was described by Liu et al. [22] and Tanhan et al. [28]: $\mathrm{BC}=$ the metal concentration in the whole plant/the metal concentration in the soil.

The translocation factor (TF) indicated the ability of plants to translocate cadmium from the roots to the shoots [29]. TF from metal concentration was calculated according to Liu et al. [22]: TF = the metal concentration in shoots/the metal concentration in roots; TF from metal accumulation $\left(\mathrm{TF}^{\prime}\right)=$ the metal accumulation in shoots/the metal accumulation in roots.

The tolerance index ( $\mathrm{Ti}$ ) was calculated to measure the ability of the plant to grow in the presence of a given concentration of metal $[3,30]$, calculated as $\mathrm{Ti}=$ dry weight 
TABLE 1: Biomass and its components (means $\pm \mathrm{SD}, n=5$ ) of $O$. fragrans var. thunbergii under different Cd supplies treatments.

\begin{tabular}{|c|c|c|c|c|c|c|}
\hline & Leaf biomass (g) & Stem biomass (g) & Root biomass (g) & Litter biomass (g) & Total $(\mathrm{g})$ & $R / S$ \\
\hline \multirow{2}{*}{ CK } & $17.96 \pm 1.46 \mathrm{a}$ & $25.38 \pm 3.99 \mathrm{a}$ & $20.72 \pm 4.06 \mathrm{a}$ & $1.61 \pm 0.60 \mathrm{a}$ & $65.67 \pm 4.58 \mathrm{a}$ & \multirow{2}{*}{$0.82 \pm 0.08 \mathrm{a}$} \\
\hline & $27.35 \%$ & $38.65 \%$ & $31.55 \%$ & $2.45 \%$ & $100 \%$ & \\
\hline \multirow{2}{*}{$\mathrm{T} 1$} & $14.82 \pm 2.08 \mathrm{a}$ & $22.28 \pm 4.44 \mathrm{ab}$ & $20.65 \pm 3.75 a$ & $1.28 \pm 0.44 a$ & $59.03 \pm 5.12 \mathrm{a}$ & \multirow{2}{*}{$0.93 \pm 0.05 b$} \\
\hline & $25.11 \%$ & $37.74 \%$ & $34.98 \%$ & $2.17 \%$ & $100 \%$ & \\
\hline \multirow{2}{*}{$\mathrm{T} 2$} & $5.62 \pm 2.97 b$ & $5.83 \pm 1.53 \mathrm{bc}$ & $6.05 \pm 1.79 b$ & $1.27 \pm 0.54 \mathrm{a}$ & $18.77 \pm 3.43 b$ & \multirow{2}{*}{$1.04 \pm 0.09 b$} \\
\hline & $29.94 \%$ & $31.06 \%$ & $32.23 \%$ & $6.77 \%$ & $100 \%$ & \\
\hline \multirow{2}{*}{ T3 } & $4.70 \pm 2.10 b$ & $5.53 \pm 1.76 b c$ & $5.60 \pm 0.96 b$ & $1.26 \pm 0.31 \mathrm{a}$ & $17.09 \pm 3.54 b$ & \multirow{2}{*}{$1.01 \pm 0.12 b$} \\
\hline & $27.50 \%$ & $32.36 \%$ & $32.77 \%$ & $7.37 \%$ & $100 \%$ & \\
\hline \multirow{2}{*}{$\mathrm{T} 4$} & $3.61 \pm 1.73 b$ & $2.52 \pm 0.52 c$ & $2.55 \pm 1.11 \mathrm{c}$ & $1.25 \pm 0.47 \mathrm{a}$ & $9.93 \pm 2.18 c$ & \multirow{2}{*}{$1.01 \pm 0.11 b$} \\
\hline & $36.35 \%$ & $25.38 \%$ & $25.68 \%$ & $12.59 \%$ & $100 \%$ & \\
\hline
\end{tabular}

Different letters within a column indicate the significant differences among the treatments $(P<.05)$.

of the plants growing in cadmium supplies/dry weight of the plants growing in control.

2.4. Statistical Analysis. The results reported are average values. Standard deviation and standard error of the mean were also calculated. Differences between treatments were tested by ANOVA followed by a LSD test after a check of normal data distribution. All statistical analysis was conducted using the SPSS (Standard released version 11.5 for Windows, SPSS Inc., IL, USA) software package.

\section{Results}

3.1. Biomass Production. Plant biomass and its components showed a decreasing tendency with the increase of Cd supplies, but which were not significantly $(P>.05)$ influenced at low levels of Cd supplies (T1; Table 1). The total biomass decreased to about $72.5 \%, 74.2 \%$, and $80.8 \%$ in $\mathrm{T} 2$, T3, and $\mathrm{T} 4$ compared with CK, respectively. Few differences in litter biomass were observed among the treatments with different amounts of $\mathrm{Cd}$ supplies, but the proportion of litter biomass to total increased with the increase of Cd supplies. The proportion of leaf biomass was higher in T4, but stem and root occupied larger proportions in other treatments. In addition, Cd supplies significantly increased the root-tostem ratio $(R / S)$.

3.2. Metal Concentration. Cd concentration in plant organs increased with the increase of $\mathrm{Cd}$ supplies, especially in leaf and stem (Figure 1). Cd concentration in root was not significantly different among T1, T2, T3, and T4. Compared with other components, stem and leaf showed higher $\mathrm{Cd}$ concentration in treatment with higher $\mathrm{Cd}$ supplies. Cd supplies increased $\mathrm{Pb}$ concentration in stem, but there were few differences among the treatments with differing $\mathrm{Cd}$ supplies. Stem and litter had higher $\mathrm{Pb}$ concentration regardless of Cd treatments compared with other components. In contrast, $\mathrm{Zn}$ and $\mathrm{Cu}$ concentration in plant organs showed a decreasing tendency with the increase of Cd supplies, except for an insignificant difference between $\mathrm{T} 1$ and CK.
$\mathrm{Zn}$ and $\mathrm{Cu}$ concentrations in stem were not significantly different among the treatments. Root had higher $\mathrm{Zn}$ and $\mathrm{Cu}$ concentration compared with other components.

3.3. $\mathrm{Cd}, \mathrm{Pb}, \mathrm{Zn}$, and $\mathrm{Cu}$ Accumulation. In comparison with other $\mathrm{Cd}$ supplies, $\mathrm{T} 1$ showed higher $\mathrm{Cd}$ accumulation in the total plant and its components except for litter, but $\mathrm{T} 2$ showed lower Cd accumulations (Table 2). Litter Cd accumulation increased with the increase of $\mathrm{Cd}$ supplies. T1 also displayed higher $\mathrm{Pb}$ accumulation in leaf, stem, and total plant than the other treatments. The other three Cd supply levels (T2, T3, and $\mathrm{T} 4$ ) decreased $\mathrm{Pb}$ accumulation in leaf, stem, and the total plant, though $\mathrm{T} 3$ and $\mathrm{T} 4$ increased $\mathrm{Pb}$ accumulation in root and litter. $\mathrm{Zn}$ and $\mathrm{Cu}$ accumulations in leaf, stem, and the total plant decreased with the increase of $\mathrm{Cd}$ supply levels, but $\mathrm{Zn}$ and $\mathrm{Cu}$ accumulations in root were insignificantly different between $\mathrm{CK}$ and $\mathrm{T} 1$.

$\mathrm{Cd}$ supplies increased the proportion of $\mathrm{Cd}$ accumulation in leaf to the total plant but decreased the proportion in root (Figure 2$). \mathrm{Pb}$ accumulation in stem represented a majority of the accumulation in plant, though T4 increased the proportion of $\mathrm{Pb}$ accumulation in litter and root to the total plant and decreased the proportion in stem. The proportion of $\mathrm{Zn}$ accumulation in leaf increased with the increase of $\mathrm{Cd}$ supplies but decreased the proportion in roots. $\mathrm{Cu}$ accumulation in root represented a majority of the accumulation in the plant. Compared with the other treatments, $\mathrm{T} 4$ increased the proportion of $\mathrm{Cu}$ accumulation in litter, but decreased $\mathrm{Cu}$ accumulation in root.

Additionally, $\mathrm{BC}$ of $\mathrm{Cd}$ in plant decreased with the increase of $\mathrm{Cd}$ supplies, but $\mathrm{BC}$ of $\mathrm{Pb}$ increased (Table 3). Compared with CK, T1 had few effects on BC of Zn and $\mathrm{Cu}$, both of which displayed a decreasing tendency with the increase of $\mathrm{Cd}$ supplies in other treatments. There were insignificant differences in $\mathrm{Tf}$ of $\mathrm{Cd}$ between $\mathrm{T} 1$ and $\mathrm{CK}$, but Tf of Cd increased with the increase of other Cd supplies. T1 and $\mathrm{T} 2$ increased the $\mathrm{Tf}$ of $\mathrm{Pb}$, but $\mathrm{T} 3$ and $\mathrm{T} 4$ decreased it. $\mathrm{Tf}$ of $\mathrm{Zn}$ and $\mathrm{Cu}$ increased with the increase of $\mathrm{Cd}$ supplies. There were few differences in $\mathrm{Tf}^{\prime}$ of $\mathrm{Cd}$ among CK, T2, T3, 
TABLE 2: The accumulation of $\mathrm{Cd}, \mathrm{Pb}, \mathrm{Zn}$, and $\mathrm{Cu}$ (Means $\pm \mathrm{SD}, n=5$ ) of $O$. fragrans var. thunbergii under different $\mathrm{Cd}$ supplies treatments.

\begin{tabular}{|c|c|c|c|c|c|c|}
\hline & & Leaf $(\mu \mathrm{g})$ & Stem $(\mu \mathrm{g})$ & $\operatorname{Root}(\mu \mathrm{g})$ & Litter $(\mu \mathrm{g})$ & Total $(\mu \mathrm{g})$ \\
\hline \multirow{5}{*}{$\mathrm{Cd}$} & CK & $15.10 \pm 2.52$ & $73.52 \pm 16.86$ & $50.18 \pm 9.54$ & $1.13 \pm 0.32$ & $139.93 \pm 28.55$ \\
\hline & $\mathrm{T} 1$ & $267.17 \pm 18.40$ & $415.32 \pm 171.01$ & $384.60 \pm 68.71$ & $1.54 \pm 0.49$ & $1068.63 \pm 218.21$ \\
\hline & $\mathrm{T} 2$ & $130.31 \pm 45.71$ & $234.49 \pm 103.86$ & $162.07 \pm 46.97$ & $6.30 \pm 1.25$ & $533.17 \pm 169.76$ \\
\hline & $\mathrm{T} 3$ & $262.82 \pm 113.29$ & $271.26 \pm 106.70$ & $189.23 \pm 82.67$ & $8.72 \pm 3.23$ & $732.03 \pm 303.44$ \\
\hline & $\mathrm{T} 4$ & $231.89 \pm 92.64$ & $236.19 \pm 139.83$ & $168.18 \pm 89.85$ & $11.93 \pm 4.11$ & $648.19 \pm 314.43$ \\
\hline \multirow{5}{*}{$\mathrm{Pb}$} & CK & $7.84 \pm 1.52$ & $42.90 \pm 14.84$ & $5.94 \pm 1.39$ & $1.83 \pm 0.45$ & $58.51 \pm 16.75$ \\
\hline & $\mathrm{T} 1$ & $14.66 \pm 1.13$ & $77.16 \pm 43.64$ & $11.26 \pm 3.61$ & $1.22 \pm 0.44$ & $104.31 \pm 46.38$ \\
\hline & $\mathrm{T} 2$ & $4.40 \pm 2.09$ & $25.23 \pm 11.88$ & $3.73 \pm 0.66$ & $1.76 \pm 0.59$ & $35.11 \pm 13.62$ \\
\hline & T3 & $5.96 \pm 2.78$ & $29.46 \pm 21.20$ & $6.80 \pm 4.68$ & $3.11 \pm 1.22$ & $45.34 \pm 29.51$ \\
\hline & $\mathrm{T} 4$ & $4.46 \pm 1.84$ & $13.19 \pm 7.89$ & $11.93 \pm 6.78$ & $3.36 \pm 0.99$ & $32.95 \pm 15.48$ \\
\hline \multirow{5}{*}{$\mathrm{Zn}$} & $\mathrm{CK}$ & $653.30 \pm 121.58$ & $480.55 \pm 194.63$ & $817.69 \pm 199.47$ & $48.46 \pm 18.64$ & $2000.00 \pm 483.37$ \\
\hline & $\mathrm{T} 1$ & $612.63 \pm 56.66$ & $387.52 \pm 177.96$ & $862.69 \pm 244.22$ & $63.61 \pm 16.08$ & $1926.44 \pm 439.41$ \\
\hline & $\mathrm{T} 2$ & $123.47 \pm 54.24$ & $104.25 \pm 53.36$ & $192.83 \pm 34.63$ & $32.00 \pm 11.29$ & $452.56 \pm 119.87$ \\
\hline & $\mathrm{T} 3$ & $111.97 \pm 60.01$ & $101.48 \pm 69.52$ & $203.90 \pm 103.99$ & $26.87 \pm 15.09$ & $444.22 \pm 244.16$ \\
\hline & $\mathrm{T} 4$ & $51.05 \pm 27.55$ & $49.81 \pm 30.92$ & $139.99 \pm 97.52$ & $18.25 \pm 9.86$ & $259.10 \pm 148.78$ \\
\hline \multirow{5}{*}{$\mathrm{Cu}$} & $\mathrm{CK}$ & $120.45 \pm 22.64$ & $250.74 \pm 102.30$ & $749.71 \pm 182.63$ & $12.35 \pm 4.61$ & $1133.24 \pm 294.19$ \\
\hline & $\mathrm{T} 1$ & $104.10 \pm 13.91$ & $202.95 \pm 80.54$ & $769.73 \pm 218.17$ & $8.15 \pm 3.62$ & $1084.93 \pm 283.74$ \\
\hline & $\mathrm{T} 2$ & $23.92 \pm 9.52$ & $54.26 \pm 28.27$ & $174.90 \pm 29.50$ & $8.44 \pm 2.42$ & $261.52 \pm 60.21$ \\
\hline & $\mathrm{T} 3$ & $18.54 \pm 6.30$ & $52.52 \pm 28.57$ & $175.47 \pm 114.84$ & $8.21 \pm 4.65$ & $254.74 \pm 153.63$ \\
\hline & $\mathrm{T} 4$ & $5.29 \pm 2.99$ & $21.21 \pm 13.63$ & $37.95 \pm 26.03$ & $5.49 \pm \pm 1.75$ & $69.95 \pm 41.78$ \\
\hline
\end{tabular}

TABLE 3: Bioaccumulation coefficient (BC), transport factor from concentration ( $\mathrm{Tf}$ ) and from accumulation ( $\left.\mathrm{Tf}^{\prime}\right)$, and tolerance index ( $\mathrm{Ti}$ ) of (Means $\pm \mathrm{SD}, n=5$ ) of $\mathrm{O}$. fragrans var. thunbergii under different Cd supplies treatments.

\begin{tabular}{|c|c|c|c|c|c|}
\hline & & $\mathrm{BC}$ & Tf & $\mathrm{Tf}^{\prime}$ & $\mathrm{Ti}$ \\
\hline \multirow{5}{*}{$\mathrm{Cd}$} & $\mathrm{CK}$ & $0.77 \pm 0.05$ & $1.20 \pm 0.06$ & $1.47 \pm 0.04$ & 1.00 \\
\hline & $\mathrm{T} 1$ & $0.66 \pm 0.04$ & $1.19 \pm 0.43$ & $1.08 \pm 0.09$ & $0.86 \pm 0.05$ \\
\hline & $\mathrm{T} 2$ & $0.60 \pm 0.13$ & $1.40 \pm 0.23$ & $1.45 \pm 0.23$ & $0.24 \pm 0.06$ \\
\hline & $\mathrm{T} 3$ & $0.37 \pm 0.12$ & $1.59 \pm 0.31$ & $1.43 \pm 0.32$ & $0.18 \pm 0.03$ \\
\hline & $\mathrm{T} 4$ & $0.27 \pm 0.02$ & $2.39 \pm 0.13$ & $1.40 \pm 0.10$ & $0.11 \pm 0.03$ \\
\hline \multirow{5}{*}{$\mathrm{Pb}$} & CK & $0.03 \pm 0.01$ & $5.68 \pm 0.10$ & $7.22 \pm 0.63$ & - \\
\hline & $\mathrm{T} 1$ & $0.05 \pm 0.01$ & $7.60 \pm 0.66$ & $6.85 \pm 0.59$ & - \\
\hline & $\mathrm{T} 2$ & $0.06 \pm 0.00$ & $6.66 \pm 0.32$ & $6.75 \pm 0.15$ & - \\
\hline & T3 & $0.07 \pm 0.02$ & $4.68 \pm 0.42$ & $4.34 \pm 0.18$ & - \\
\hline & $\mathrm{T} 4$ & $0.08 \pm 0.01$ & $1.87 \pm 0.16$ & $1.11 \pm 0.04$ & - \\
\hline \multirow{5}{*}{$\mathrm{Zn}$} & CK & $0.26 \pm 0.00$ & $0.45 \pm 0.00$ & $0.59 \pm 0.04$ & - \\
\hline & $\mathrm{T} 1$ & $0.27 \pm 0.00$ & $0.51 \pm 0.00$ & $0.45 \pm 0.05$ & - \\
\hline & $\mathrm{T} 2$ & $0.22 \pm 0.01$ & $0.52 \pm 0.00$ & $0.54 \pm 0.03$ & - \\
\hline & $\mathrm{T} 3$ & $0.19 \pm 0.01$ & $0.51 \pm 0.01$ & $0.50 \pm 0.04$ & - \\
\hline & $\mathrm{T} 4$ & $0.18 \pm 0.02$ & $0.64 \pm 0.01$ & $0.36 \pm 0.01$ & - \\
\hline \multirow{5}{*}{$\mathrm{Cu}$} & $\mathrm{CK}$ & $0.62 \pm 0.01$ & $0.26 \pm 0.02$ & $0.33 \pm 0.08$ & - \\
\hline & $\mathrm{T} 1$ & $0.63 \pm 0.24$ & $0.30 \pm 0.08$ & $0.26 \pm 0.07$ & - \\
\hline & $\mathrm{T} 2$ & $0.52 \pm 0.09$ & $0.31 \pm 0.09$ & $0.31 \pm 0.08$ & - \\
\hline & $\mathrm{T} 3$ & $0.45 \pm 0.04$ & $0.34 \pm 0.02$ & $0.30 \pm 0.02$ & - \\
\hline & $\mathrm{T} 4$ & $0.20 \pm 0.08$ & $1.00 \pm 0.23$ & $0.56 \pm 0.05$ & - \\
\hline
\end{tabular}

and $\mathrm{T} 4$, but $\mathrm{Tf}^{\prime}$ of $\mathrm{Cd}$ decreased in $\mathrm{T} 1 . \mathrm{Tf}^{\prime}$ of $\mathrm{Pb}$ and $\mathrm{Zn}$ decreased with the increase of $\mathrm{Cd}$ supplies. $\mathrm{Tf}^{\prime}$ of $\mathrm{Cu}$ was higher in T4, although it showed few differences in the other four treatments. Ti of $\mathrm{Cd}$ decreased with the increase of $\mathrm{Cd}$ supplies, but it reached 0.86 in $\mathrm{T} 1$.

\section{Discussion}

The hypothesis that Cd supplies would decrease the growth of osmanthus and decrease the accumulation of other metals was only partly demonstrated in this study. Biomass 


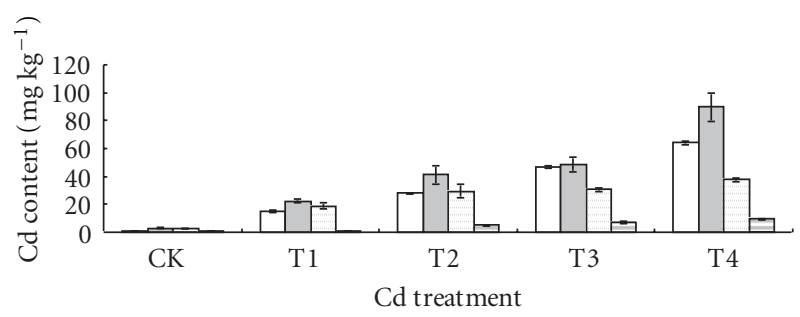

(a)

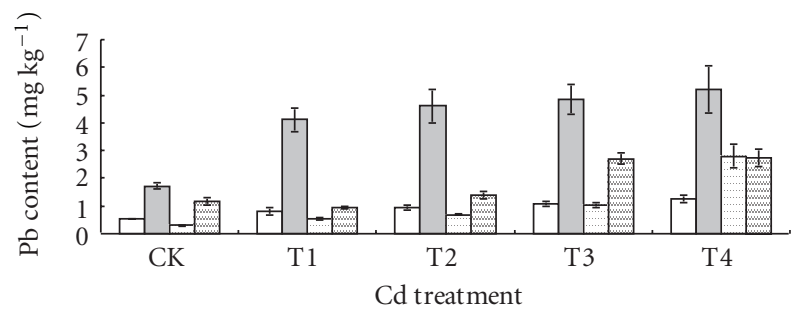

(b)

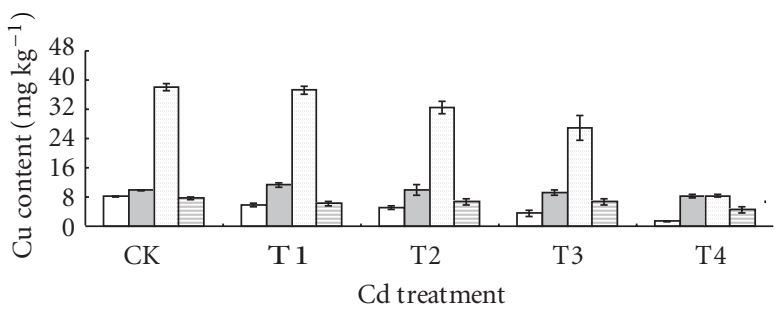

(c)

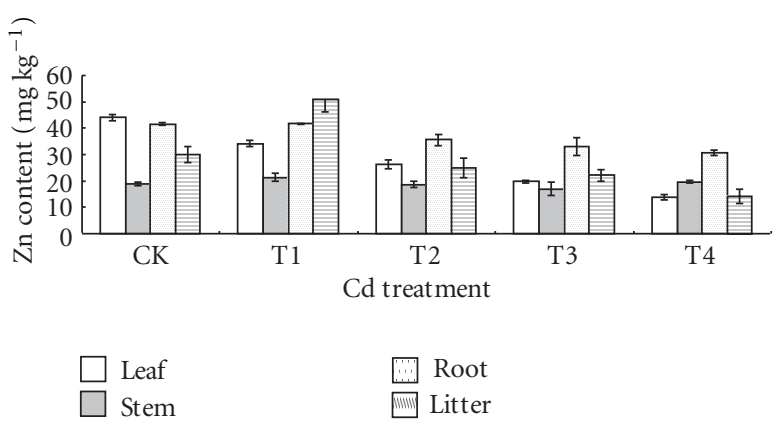

(d)

Figure 1: $\mathrm{Cd}, \mathrm{Pb}, \mathrm{Zn}$, and $\mathrm{Cu}$ concentrations of $\mathrm{O}$. fragrans var. thunbergii under different treatments with different $\mathrm{Cd}$ supplies. Bars indicate SD, $n=5$.

and its components showed a decreasing tendency as Cd supply increased, but no significant differences were observed between the treatments with the low $\mathrm{Cd}$ supply (25 $\mathrm{mg} \mathrm{Cd} \mathrm{kg}^{-1}$ ) and no Cd supply. Furthermore, the low Cd supply (T1) clearly increased the accumulation of $\mathrm{Cd}$ and $\mathrm{Pb}$, but the other $\mathrm{Cd}$ supplies decreased the accumulation of $\mathrm{Pb}, \mathrm{Zn}$, and $\mathrm{Cu}$. This is in agreement with the observation from Liu et al. [13] that one heavy metal could facilitate the accumulation of another. However, this only occurred in the treatment with low Cd supply, the higher Cd contamination significantly decreased the accumulation of other metals because of the obvious decrease in the production of plant biomass.

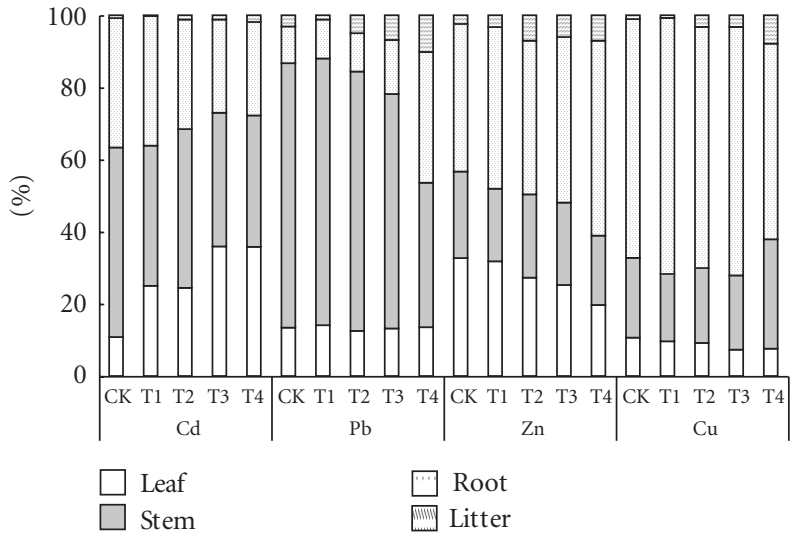

Figure 2: $\mathrm{Cd}, \mathrm{Pb}, \mathrm{Zn}$, and $\mathrm{Cu}$ partitioning of $\mathrm{O}$. fragrans var. thunbergii under different treatments with different $\mathrm{Cd}$ supplies.

Adaptive responses in biomass production and its distribution may be a primary mechanism by which the species can cope with the environmental characteristics of their respective habitats [31]. Since heavy metals often induce low availability of soil resources and limit the absorption ability of root, decreased biomass production has often been detected in habitats with heavy metal contamination $[6,16,20]$. The results here also support this theory, but the low Cd supply (T1) did not significantly decrease biomass production and its components, suggesting the examined osmanthus could adapt to the Cd-contaminated environment with a little harm. It is essential to note that $\mathrm{Cd}$ supplies significantly increased the ratio of $R / S$, which is the direct evidence of adaptation responses on the part of osmanthus to the Cd contaminated habitat. Additionally, leaf biomass represented a higher proportion of total plant biomass in the highest Cd supplies (T4), a finding which indicated a maximum carbon-fixation adaptation mechanism in respond to a heavy environmental factor stress. Wu et al. [31] have also observed similar phenomenon in the heavy drought stress environment.

Metal accumulation of plant was determined by biomass production and metal concentration in plant components. Although biomass production was decreased in response to Cd supplies, the concentration of examined metals in plant components did show inconsistent responses to different levels of $\mathrm{Cd}$ supplies. $\mathrm{Cd}$ and $\mathrm{Pb}$ concentration in the plant components showed an increasing tendency with the increase of Cd supplies. Many previous studies have observed that $\mathrm{Cd}$ concentration in plant components increased with the increase of Cd supplies except for excluder plants [16, 32], which suggested that the plant employs the accumulation mechanism [33]. Higher $\mathrm{Pb}$ concentration in stem was also observed in the treatment with $\mathrm{Cd}$ supplies compared with no Cd supply in this study, which is further support for the theory that one heavy metal could facilitate the accumulation of another [13]. Moreover, due to higher $\mathrm{Pb}$ concentration in shoot compared with that in root (Figure 1), osmanthus might have an efficient translocation ability that transferred $\mathrm{Pb}$ from root to shoot. In contrast to $\mathrm{Cd}$ and $\mathrm{Pb}, \mathrm{Zn}$ and $\mathrm{Cu}$ 
concentration in plant components displayed a decreasing tendency as Cd supplies increased. The observations here agree with the results on tobacco from Vasiliadou and Dordas [11], indicating that $\mathrm{Cd}$ contamination could limit the absorption of $\mathrm{Zn}$ and $\mathrm{Cu}$, and could also affect the transfer efficiency from root to shoot due to relative higher root $\mathrm{Zn}$ and $\mathrm{Cu}$ concentration. Tf of $\mathrm{Zn}$ and $\mathrm{Cu}$ also showed a similar pattern (Table 3 ). $\mathrm{Zn}$ and $\mathrm{Cu}$ are essential micronutrients required for proper physiological and metabolic functioning of plants, and are only toxic at high concentrations [34]. Heavy Cd contamination might lead to a deficiency of $\mathrm{Zn}$ and $\mathrm{Cu}$, which could be one of the main reasons for the limited growth of osmanthus in the Cd contaminated environment.

Low Cd supply treatment (T1) had insignificant effects on biomass production, but significantly increased $\mathrm{Cd}$ and $\mathrm{Pb}$ concentration in plant organs, osmanthus in $\mathrm{T} 1 \mathrm{accu}-$ mulated more $\mathrm{Cd}$ and $\mathrm{Pb}$ compared with that in other treatments. This suggested that metal phytoextraction using the examined osmanthus could potentially be applied to clean up soils moderately contaminated by $\mathrm{Cd}$ and $\mathrm{Pb}$ in this environment. Meanwhile, the results also showed that $\mathrm{Cd}$ supplies increased the proportion of leaf Cd accumulation, and the proportion of stem $\mathrm{Pb}$ accumulation that occupied the majority of total $\mathrm{Pb}$ accumulation, implying that $\mathrm{Cd}$ and $\mathrm{Pb}$ have relatively higher transfer ability in this examined osmanthus, and Cd toxicity is primarily harmful to leaves, which agreed with the previous studies [3, 20]. However, high $\mathrm{Cd}$ contamination level could decrease $\mathrm{Pb}$ accumulation and limited $\mathrm{Pb}$ transfer from root to shoot in osmanthus by limiting plant growth and stem $\mathrm{Pb}$ accumulation. As mentioned above, $\mathrm{Cd}$ supplies limited the transfer of $\mathrm{Zn}$ and $\mathrm{Cu}$ in osmanthus, so that the above-ground accumulation of $\mathrm{Zn}$ and $\mathrm{Cu}$ decreased with the increase of Cd supplies. Insignificant differences of root $\mathrm{Zn}$ and $\mathrm{Cu}$ accumulation between $\mathrm{CK}$ and the low Cd supply treatment could be related to the insignificant differences in root biomass.

Many previous studies have documented that four indicators (the threshold value of metal, BC, Tf, and Ti) could be used to determine the metal accumulation efficiency of plant $[16,17,35]$. The threshold value of metal was not examined here, only $\mathrm{Ti}$ of $\mathrm{Cd}$ was examined, the results from the $\mathrm{BC}$, $\mathrm{Tf}, \mathrm{Tf}^{\prime}$ were inconsistent among $\mathrm{Cd}, \mathrm{Pb}, \mathrm{Zn}$, and $\mathrm{Cu}$ in response to different $\mathrm{Cd}$ supplies. Even so, the synthesized analysis implied that osmanthus had an efficient transfer efficiency of $\mathrm{Cd}$ and $\mathrm{Pb}$ since both $\mathrm{Tf}$ and $\mathrm{Tf}^{\prime}>$ 1.0 , even $\mathrm{Tf}$ and $\mathrm{Tf}^{\prime}$ of $\mathrm{Pb}>4.0$ in relatively low $\mathrm{Cd}$ supplies treatments (CK, T1, T2, and T3). Both Tf and $\mathrm{Tf}^{\prime}$ of $\mathrm{Pb}$ were higher than those of $\mathrm{Cd}, \mathrm{Zn}$, and $\mathrm{Cu}$, which could be explained by two different explanations. First, the appearance of $\mathrm{Cd}$ promoted the transfer of $\mathrm{Pb}$ from root to shoot since $\mathrm{BC}$ of $\mathrm{Pb}$ increased with the increase of $\mathrm{Cd}$ supplies. Second, the examined osmanthus could be a potential $\mathrm{Pb}$ hyperaccumulator with high $\mathrm{Pb}$ accumulation efficiency. These two issues warrant further study. In contrast, decreased $\mathrm{Zn}$ and $\mathrm{Cu}$ accumulation in osmanthus mainly resulted from Cd limitation, since both $\mathrm{Tf}$ and $\mathrm{Tf}^{\prime}$ were far less than 1.0, and $\mathrm{BC}$ of $\mathrm{Zn}$ and $\mathrm{Cu}$ decreased with the increase of $\mathrm{Cd}$ supplies. Although osmanthus would not be a potential $\mathrm{Cd}$ hyperaccumulator in this environment since $\mathrm{BC}<0.8$ and decreased with the increase of Cd concentration in the soil, osmanthus could grow well under the region with low Cd contamination ( $25 \mathrm{mg} \mathrm{Cd} \mathrm{kg}^{-1}$ dry soil), since Ti reached 0.86 .

\section{Conclusions}

Cd supplies decreased biomass and its components in osmanthus, but there were no significant differences between the low Cd supply treatment $\left(25 \mathrm{mg} \mathrm{Cd} \mathrm{kg}^{-1}\right)$ and no $\mathrm{Cd}$ supply. Low Cd supply also significantly increased the accumulation of $\mathrm{Cd}$ and $\mathrm{Pb}$, although the other $\mathrm{Cd}$ supplies decreased the accumulation of $\mathrm{Pb}, \mathrm{Zn}$, and $\mathrm{Cu}$. The examined osmanthus showed efficient $\mathrm{Cd}$ - and $\mathrm{Pb}$-transfer efficiency in the presence of $\mathrm{Cd}$ supplies. Cd supplies could limit the absorption and transfer of $\mathrm{Zn}$ and $\mathrm{Cu}$. Therefore, the osmanthus has potential for phytoremediation application in $\mathrm{Cd}$ and $\mathrm{Pb}$ contaminated soil, and the plant could grow well in the low Cd-contaminated soil. More work should be done to reveal the responses of metal accumulation and plant growth under low metal-contamination level.

\section{Acknowledgments}

The paper was financially supported by the programs of the Key Project of Public Welfare Research of Sichuan (no. 2007NGY006), Sichuan Provisional Key Technologies R \& D, China (no. 2010SZ0051), and the Key Cultivation Programs of the Education Department of Sichuan Province (07ZZ024 and 09ZZ023).

\section{References}

[1] J. Feng, Q. Shi, X. Wang, M. Wei, F. Yang, and H. Xu, "Silicon supplementation ameliorated the inhibition of photosynthesis and nitrate metabolism by cadmium (Cd) toxicity in Cucumis sativus L," Scientia Horticulturae, vol. 123, no. 4, pp. 521-530, 2010.

[2] S. Folgar, E. Torres, M. Pérez-Rama, A. Cid, C. Herrero, and J. Abalde, "Dunaliella salina as marine microalga highly tolerant to but a poor remover of cadmium," Journal of Hazardous Materials, vol. 165, no. 1-3, pp. 486-493, 2009.

[3] M. Zacchini, F. Pietrini, G. Scarascia Mugnozza, V. Iori, L. Pietrosanti, and A. Massacci, "Metal tolerance, accumulation and translocation in poplar and willow clones treated with cadmium in hydroponics," Water, Air, and Soil Pollution, vol. 197, no. 1-4, pp. 23-34, 2009.

[4] K. Chojnacka, "Biosorption and bioaccumulation-the prospects for practical applications," Environment International, vol. 36, no. 3, pp. 299-307, 2010.

[5] P. Licata, F. Naccari, V. Lo Turco, R. Rando, G. Di Bella, and G. Dugo, "Levels of Cd (II), Mn (II), Pb (II), Cu (II), and $\mathrm{Zn}$ (II) in common buzzard (Buteo buteo) from Sicily (Italy) by derivative stripping potentiometry," International Journal of Ecology, vol. 2010, Article ID 541948, 7 pages, 2010.

[6] M. P. Benavides, S. M. Gallego, and M. L. Tomaro, "Cadmium toxicity in plants," Brazilian Journal of Plant Physiology, vol. 17, no. 1, pp. 21-34, 2005.

[7] Y. G. Zhu, Z. Q. Zhao, H. Y. Li, S. E. Smith, and F. A. Smith, "Effect of zinc-cadmium interactions on the uptake of zinc 
and cadmium by winter wheat (Triticum aestivum) grown in pot culture," Bulletin of Environmental Contamination and Toxicology, vol. 71, no. 6, pp. 1289-1296, 2003.

[8] Z. Q. Zhao, Y. G. Zhu, and Y. L. Cai, "Effects of zinc on cadmium uptake by spring wheat (Triticum aestivum, L.): long-time hydroponic study and short-time ${ }^{109} \mathrm{Cd}$ tracing study," Journal of Zhejiang University, vol. 6, no. 7, pp. 643648, 2005.

[9] B. Nedjimi and Y. Daoud, "Cadmium accumulation in Atriplex halimus subsp. schweinfurthii and its influence on growth, proline, root hydraulic conductivity and nutrient uptake," Flora, vol. 204, no. 4, pp. 316-324, 2009.

[10] C. C. Lin, H. Y. Lai, and Z. S. Chen, "Bioavailability assessment and accumulation by five garden flower species grown in artificially cadmium-contaminated soils," International Journal of Phytoremediation, vol. 12, no. 5, pp. 454-467, 2010.

[11] S. Vasiliadou and C. Dordas, "Increased concentration of soil cadmium affects on plant growth, dry matter accumulation, $\mathrm{Cd}$, and $\mathrm{Zn}$ uptake of different tobacco cultivars (Nicotiana tabacum L.)," International Journal of Phytoremediation, vol. 11, no. 2, pp. 115-130, 2009.

[12] J. Patrn, N. Lonka, and B. B. Panda, "Tolerance and cotolerance of the grass Chloris barbataa SW. to mercury, cadmium and zinc," New Phytologist, vol. 128, pp. 165-171, 1994.

[13] J. N. Liu, Q. X. Zhou, T. Sun, L. Q. Ma, and S. Wang, "Growth responses of three ornamental plants to $\mathrm{Cd}$ and $\mathrm{Cd}-\mathrm{Pb}$ stress and their metal accumulation characteristics," Journal of Hazardous Materials, vol. 151, no. 1, pp. 261-267, 2008.

[14] T. Makino, K. Sugahara, Y. Sakurai et al., "Remediation of cadmium contamination in paddy soils by washing with chemicals: selection of washing chemicals," Environmental Pollution, vol. 144, no. 1, pp. 2-10, 2006.

[15] S. P. McGrath, E. Lombi, C. W. Gray, N. Caille, S. J. Dunham, and F. J. Zhao, "Field evaluation of Cd and Zn phytoextraction potential by the hyperaccumulators Thlaspi caerulescens and Arabidopsis halleri," Environmental Pollution, vol. 141, no. 1, pp. 115-125, 2006.

[16] Y. B. Sun, Q. X. Zhou, W. T. Liu, J. An, Z. Q. Xu, and L. Wang, "Joint effects of arsenic and cadmium on plant growth and metal bioaccumulation: a potential Cd-hyperaccumulator and As-excluder Bidens pilosa L," Journal of Hazardous Materials, vol. 165, no. 1-3, pp. 1023-1028, 2009.

[17] Q. X. Zhou, S. H. Wei, and Q. R. Zhang, Ecological Remediation, Chinese Environmental Science Press, Beijing, China, 2004.

[18] M. N. V. Prasad, "Phytoremediation of metal-polluted ecosystems: hype for commercialization," Russian Journal of Plant Physiology, vol. 50, no. 5, pp. 686-700, 2003.

[19] F. Pietrini, M. Zacchini, V. Iori, L. Pietrosanti, D. Bianconi, and A. Massacci, "Screening of poplar clones for cadmium phytoremediation using photosynthesis, biomass and cadmium content analyses," International Journal of Phytoremediation, vol. 12, no. 1, pp. 105-120, 2010.

[20] F. Wu, W. Yang, J. Zhang, and L. Zhou, "Cadmium accumulation and growth responses of a poplar (Populus deltoids $\times$ Populus nigra) in cadmium contaminated purple soil and alluvial soil," Journal of Hazardous Materials, vol. 177, no. 1-3, pp. 268-273, 2010.

[21] Y. A. Kuzovkina, M. Knee, and M. F. Quigley, "Cadmium and copper uptake and translocation in five willow (Salix L.) species," International Journal of Phytoremediation, vol. 6, no. 3, pp. 269-287, 2004.
[22] Z. Liu, X. He, W. Chen, F. Yuan, K. Yan, and D. Tao, "Accumulation and tolerance characteristics of cadmium in a potential hyperaccumulator-Lonicera japonica Thunb," Journal of Hazardous Materials, vol. 169, no. 1-3, pp. 170-175, 2009.

[23] B. Du, W. Q. Yang, and J. Zhang, "Investigation and assessment on soil heavy metal contamination in the mountain-hilly transitive zone: a case from Wutongqiao county, Sichuan," Journal of Mountain Science, vol. 24, pp. 82-87, 2006.

[24] Sichuan Office of Soil Survey, Sichuan Soil, Sichuan Science \& Technology Press, Chengdu, Chjina, 1995.

[25] J. Zhang, Integrated Management on Soil and Water Loss in the Hilly Area and Regional Sustainable Development in Sichuan Province, Sichuan Science \& Technology Press, Chengdu, Chjina, 2009.

[26] X. E. Yang, X. X. Long, H. B. Ye, Z. L. He, D. V. Calvert, and P. J. Stoffella, "Cadmium tolerance and hyperaccumulation in a new Zn-hyperaccumulating plant species (Sedum alfredii Hance)," Plant and Soil, vol. 259, no. 1-2, pp. 181-189, 2004.

[27] Y. L. Han, H. Y. Yuan, S. Z. Huang, Z. Guo, B. Xia, and J. Gu, "Cadmium tolerance and accumulation by two species of Iris," Ecotoxicology, vol. 16, no. 8, pp. 557-563, 2007.

[28] M. K. P. Tanhan, M. Kruatrachue, P. Pokethitiyook, and R. Chaiyarat, "Uptake and accumulation of cadmium, lead and zinc by Siam weed [Chromolaena odorata (L.) King \&amp; Robinson]," Chemosphere, vol. 68, no. 2, pp. 323-329, 2007.

[29] M. I. Mattina, W. Lannucci-Berger, C. Musante, and J. C. White, "Concurrent plant uptake of heavy metals and persistent organic pollutants from soil," Environmental Pollution, vol. 124, no. 3, pp. 375-378, 2003.

[30] D. A. Wilkins, "The measurement of tolerance to edaphic factors by means of root growth," New Phytologist, vol. 80, pp. 623-633, 1978.

[31] F. Wu, W. Bao, F. Li, and N. Wu, "Effects of drought stress and $\mathrm{N}$ supply on the growth, biomass partitioning and water-use efficiency of Sophora davidii seedlings," Environmental and Experimental Botany, vol. 65, no. 1-3, pp. 248-255, 2008.

[32] J. Yanai, F. J. Zhao, S. P. McGrath, and T. Kosaki, "Effect of soil characteristics on Cd uptake by the hyperaccumulator Thlaspi caerulescens," Environmental Pollution, vol. 139, no. 1, pp. 167175, 2006.

[33] A. J. M. Baker, "Metal tolerance," New Phytologist, vol. 106, no. 1, pp. 93-111, 1987.

[34] Z. Hassan and G. M. A. Mark, "Opportunities and feasibilities forbiotechnological improvement of $\mathrm{Zn}, \mathrm{Cd}$ or Ni tolerance and accumulation in plants," Environmental and Experimental Botany, vol. 72, no. 1, pp. 53-63, 2011.

[35] A. J. M. Baker, "Accumulators and excluders-strategies in the response of plants to heavy metals," Journal of Plant Nutrition, vol. 3, pp. 643-654, 1981. 

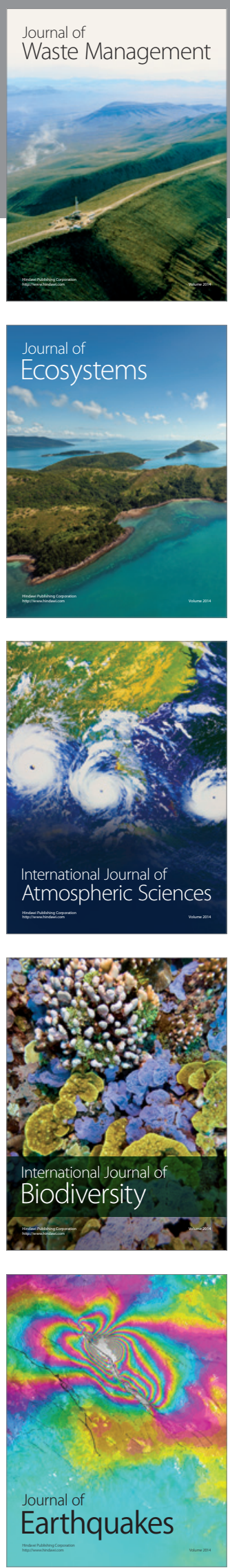
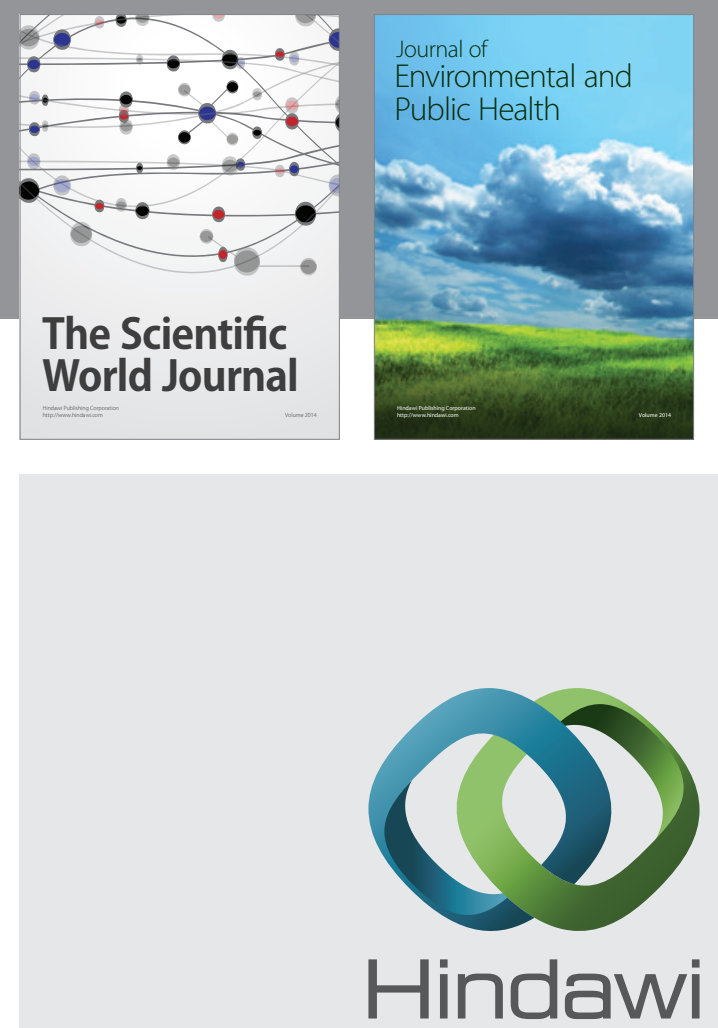

Submit your manuscripts at

http://www.hindawi.com
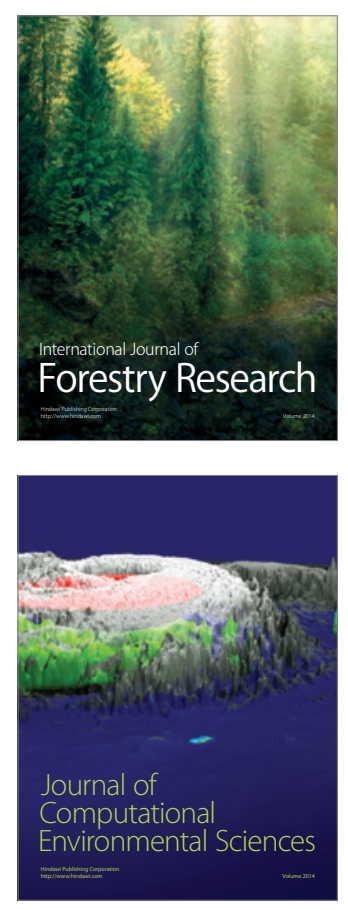
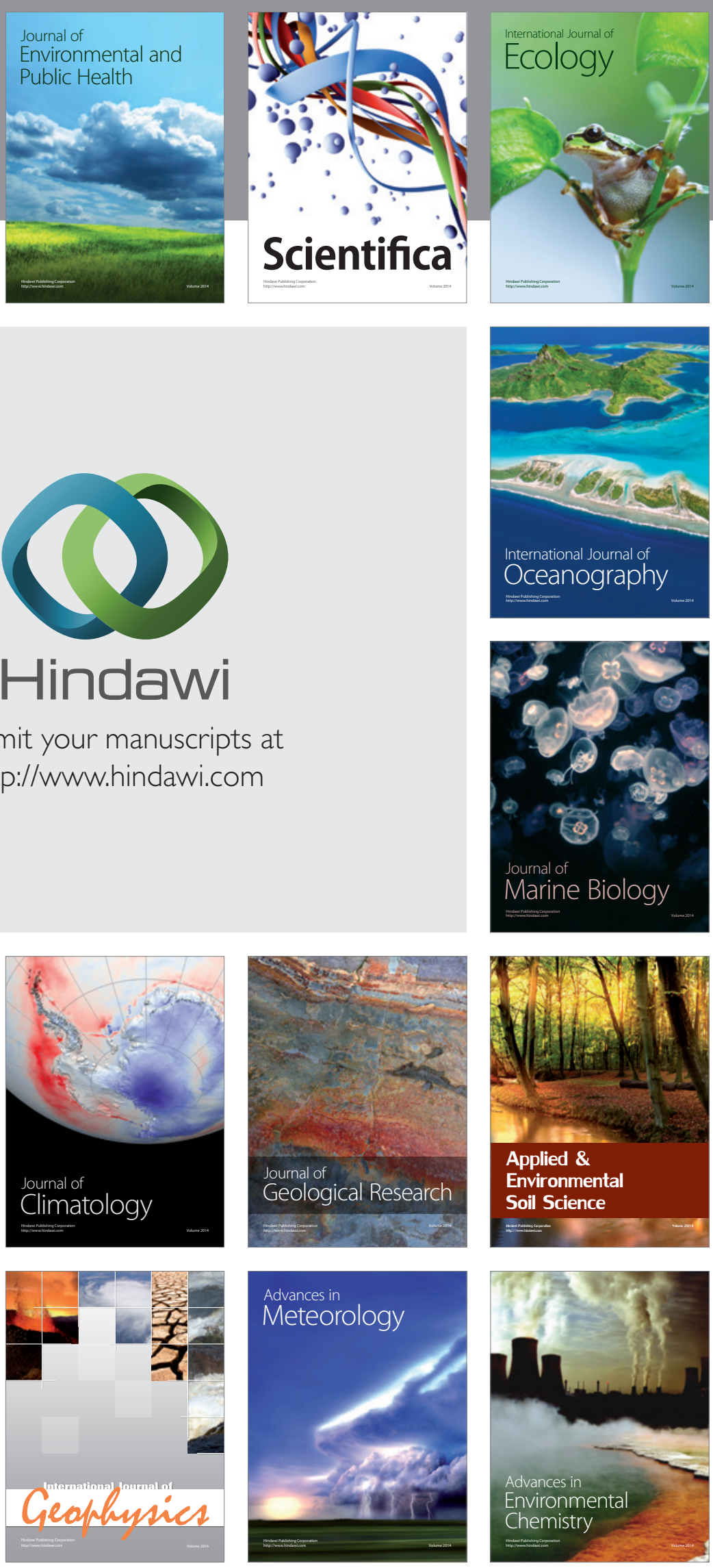